\title{
trends
}

\section{A Programmed Audiovisual Orientation to an Outpatient Clinic}

\author{
MARGARET A. BRACKIN, RN, and
}

RONALD A. CHEZ, MD

A programmed audiovisual introduction to a large obstetric-gynecologic clinic was developed for and evaluated by nursing students who spent one or two weeks in the facility. This orientation is geared toward active learning and progress at each individual's rate. Data show that this orientation is an effective and efficient substitute for faculty presentation of repetitive information. In six of eight tasks evaluated, students in a programmed audiovisual group required fewer days to acquire skill in performing the tasks than did students in a control group. Faculty are released to belp the student with the more sophisticated aspects of nursing care.

This project was supported by a grant from the Sarah Mellon Scaife Foundation.

Address reprint requests to Miss Margaret A. Brackin, RN, Ob/Gyn Nurse Practitioner, McKeesport Hospital, 1500 Fifth Avenue, McKeesport, Pennsylvania 15132.
During the clinical portion of the nursing school curriculum, the student spends short periods in a number of inpatient and outpatient settings. In each new environment a faculty member must provide an orientation. We have found that when this type of orientation is repeated at frequent intervals for small groups of students, the consistency and enthusiasm of the faculty presentation tends to be unpredictable. In some instances the instructor may be unaware that the students are not learning the material. This is particularly true if the instructor believes the information being discussed is obvious. This relates to Gold's COIK (Clear Only If Known) fallacy. ${ }^{1}$

This paper deals with the orientation experience for second and third year nursing students in the Obstetrics-Gynecology Medical Care Center at Magee-Womens Hospital at the University Health Center of Pittsburgh. Students from four nursing programs spend one or two weeks in the Medical Care Center studying the physical and psychologic components of pregnancy and gynecologic disease. 
To enhance the student's feeling of personal and professional comfort in this environment, it is essential that she quickly and efficiently learn the routines and procedures used in the setting. This orientation base will allow the student to assist the physician and to participate actively in basic care of patients. She can then achieve more sophisticated levels of nursing knowledge.

Prior to the programmed audiovisual introduction to the Medical Care Center, student orientation consisted of a faculty lecture and demonstration of the routines and procedures used at the Center. A new group of six diploma students rotated through the Medical Care Center each week; in addition, nine groups of five to eight college students spent two weeks in the Center during the year.

To optimize the time spent by students and faculty, a revised orientation program, with an audiovisual, programmed approach, was developed. The following objectives were applied:

1. Present the orientation material in a consistent and efficient manner that would develop the student's responsibility and initiative for selflearning.

2. Provide an opportunity for the student to review material readily.

3. Enhance the effectiveness of the individual student-teacher contact time.

4. Shorten the time necessary for the student to become professionally competent in carrying out her duties as a member of the health team.

\section{Methods}

University of Pittsburgh faculty and generic nursing students were used to study the two orientation methods. The orientation program was varied as follows.

\section{Control Groups}

The faculty member presented the orientation by lecture and demonstration. There was a tour of the physical facilities of the Medical Care Center and a demonstration of the equipment and instruments used during physical and pelvic examinations.

\section{Programmed Audiovisual Groups}

Orientation tools used were two booklets and a slide-tape presentation. Each incorporated principles of programmed instruction. Information was presented in a sequential manner. The student actively participated by answering questions that pertained to a block of information. The student immediately reviewed the correct answer before proceeding to the next block. The student therefore worked at her own rate and received immediate feedback.

Booklet 1: The Obstetrics_Gynecology Medical Care Center of Magee-Womens Hospital is an 11page booklet containing $10 \mathrm{ink}$ diagrams of the floor plan of the department with text, the physical layout of the Medical Care Center and the position of the equipment used in the examining room. In this booklet small segments of information are immediately followed by questions pertaining to this information; correct responses appear on a subsequent page.

Booklet 2: Care of Female Patients in the Examining Room is a 21-page booklet with 24 photographs and three diagrams illustrating the text. Emphasis is on positioning and draping a patient and assisting the physician during general physical and pelvic examinations. There is also a discussion of the ways in which the nurse can foster patient relaxation during the pelvic examination and show concern for the patient's privacy. Questions are asked in the middle of the text and again at the end, with correct responses given on the back of each question page.

The slide-tape presentation, Assisting the Physician with Prenatal Examination, is 45 minutes long and illustrated with $66 \quad 35-\mathrm{mm}$ slides. The slides are automatically and silently impulsed on a separate sound track of the tape and appear on a rear view screen suitable for individual or group viewing. Emphasis is on the utilization of basic instruments and equipment, nursing routines and the application of clinical laboratory tests to prenatal 


\begin{tabular}{|c|c|c|c|c|c|c|c|c|c|}
\hline \multirow[b]{3}{*}{ Tasks/Evaluators } & \multicolumn{8}{|c|}{ Days } & \multirow[b]{3}{*}{ Significance ${ }^{\dagger}$} \\
\hline & \multicolumn{4}{|c|}{ Control group* } & \multicolumn{4}{|c|}{ Experimental group* } & \\
\hline & 1 & 2 & 3 & 4 & 1 & 2 & 3 & 4 & \\
\hline \multicolumn{10}{|c|}{ Directed patient to areas within the Center } \\
\hline Student & 5 & 6 & 2 & 2 & 12 & 15 & 4 & - & NS \\
\hline Faculty & 9 & 6 & - & - & 26 & 5 & - & - & $\mathrm{S}$ \\
\hline \multicolumn{10}{|c|}{ Helped patient change from lying to } \\
\hline Student & 3 & 8 & 3 & 1 & 16 & 10 & 4 & 1 & $\mathbf{s}$ \\
\hline Faculty & 5 & 4 & 5 & 1 & 28 & 3 & - & 一 & $\mathbf{S}$ \\
\hline \multicolumn{10}{|c|}{$\begin{array}{l}\text { Promoted patient relaxation during pelvic } \\
\text { examination }\end{array}$} \\
\hline Student & 4 & 3 & 8 & -- & 9 & 15 & 7 & - & $\mathbf{S}$ \\
\hline Faculty & - & 7 & 8 & - & 15 & 14 & 2 & - & $\mathrm{S}$ \\
\hline \multicolumn{10}{|c|}{$\begin{array}{l}\text { Remembered sequential order of physical } \\
\text { examination }\end{array}$} \\
\hline Student & 4 & 11 & - & 一 & 21 & 10 & - & - & $\mathbf{S}$ \\
\hline Faculty & - & - & 15 & - & - & 30 & 1 & - & $\mathrm{s}$ \\
\hline \multicolumn{10}{|c|}{$\begin{array}{l}\text { Remembered sequential order of pelvic } \\
\text { examination }\end{array}$} \\
\hline Student & 2 & 8 & 5 & 一 & 18 & 10 & 3 & - & $\mathrm{s}$ \\
\hline Faculty & 3 & 6 & 6 & - & 17 & 14 & - & - & $\mathbf{S}$ \\
\hline \multicolumn{10}{|c|}{$\begin{array}{l}\text { Knew which instrument to hand physician } \\
\text { during physical examination }\end{array}$} \\
\hline Student & 2 & 10 & 3 & - & 14 & 15 & - & 2 & $\mathbf{S}$ \\
\hline Faculty & - & - & 14 & 1 & 11 & 20 & - & - & $\mathbf{S}$ \\
\hline \multicolumn{10}{|c|}{$\begin{array}{l}\text { Knew which intrument to hand physician } \\
\text { during pelvic examination }\end{array}$} \\
\hline Student & 3 & 8 & 4 & - & 9 & 19 & 3 & - & NS \\
\hline Faculty & - & - & 14 & 1 & 15 & 16 & - & 一 & $\mathbf{S}$ \\
\hline \multicolumn{10}{|c|}{$\begin{array}{l}\text { Knew how to prepare Papanicolaou } \\
\text { vaginal-cervical smear }\end{array}$} \\
\hline Student & 6 & 7 & 2 & - & 27 & 4 & - & - & $\mathbf{S}$ \\
\hline Faculty & 10 & 5 & - & - & 31 & - & - & - & $\mathbf{S}$ \\
\hline
\end{tabular}

* Control group 15; experimental group 31

${ }^{\dagger} \mathrm{S}=$ significant to $0.05 ; \mathrm{NS}=$ not statistically significant

patients. A booklet, which accompanies this tape, contains a partially completed hospital prenatal form, a cytopathology requisition and summary questions. The student must complete this material during the slide presentation. Records of a patient's weight, blood pressure, and urinalysis are shown and the student is asked to interpret these data and complete the appropriate form. Again, correct responses are immediately displayed after each question.

At the end of the orientation the instructor meets with the students to answer questions, provide assignments and familiarize students with the examining room before they work with patients.

The new orientation program was evaluated by questionnaire response and structured interviews. The same evaluation format was used for both the control groups and the experimental groups. The four participating faculty members completed similar questionnaires.

\section{Results}

Table 1 is a comparison of the two orientation programs with time in days required for the student to acquire selected skills. The students' evaluations indicate that in six of the eight tasks more students in the programmed audiovisual group re- 
quired fewer days to acquire the skill than did students in the control group. There was no significant difference in the learning time required to direct a patient to areas within the Center. However no instructor time was used in the programmed audiovisual group, whereas the instructor for the control group spent 45 minutes showing the students the physical layout.

Students in both groups required about the same amount of time to learn the appropriate instrument to hand the physician during the pelvic examination. Faculty evaluation differed from the students' perception of their learning. It was the faculty's opinion that the experimental group acquired all eight skills in less time than did the students in the control group. Furthermore, faculty data does not agree with student opinion as to the number of days required by each group to learn each task.

Control group orientation took between one-half to two hours of both student and faculty time. Thirteen of the 15 students in this group rated their orientation "effective and inclusive." Over half of the group would have liked to familiarize themselves with the office and instruments following the orientation.

The programmed orientation required $1 \frac{1 / 2-2}{2}$ hours of student time. All 31 students rated the programmed audiovisual orientation "effective and inclusive." However, three students believed their orientation insulted their intelligence. One of these students commented that the material seemed picayune until she had to use the information in the clinic setting. Several students believed they learned more rapidly and remembered more readily.

All students reviewed orientation material prior to coming to the area. Specifically, of the 31 individuals, all reviewed Booklet 1, 15 reviewed Booklet 2, and 26 reviewed the material supplemental to the slide-tape presentation.

The use of faculty-student contact time was not accurately defined except by impressions of the participating faculty. Faculty contact with students from the programmed orientation appeared to deal more with direct patient-oriented problems than did that of the control group. The latter asked more about routines and procedures.

\section{Discussion}

The use of programmed instruction with audiovisual aid has received national attention. ${ }^{2,}{ }^{3}$ In this method the student must be an active learner rather than a passive listener. This approach requires that the student initiate learning at the rates and frequency needed. Faculty, the most valuable resource in a professional educational program, are free to utilize student-teacher contact time in the individualization of learning, the placement of learned material into clinical perspective, and more carefully help students observe patients based on professional experience.

Our data demonstrate that a programmed orientation with the use of audiovisual media is an effective substitute for the use of faculty in a repetitive seminar or lecture. The students accept and learn more readily from the method. It provides a more rapid acquisition of those nursing skills needed to function as a member of the health team. Introduction to a new setting with new routines and new instruments can be anxiety producing. It is our belief that anxiety can be reduced by allowing the student to proceed at her own pace during orientation and to review when necessary.

When faculty members are freed from the repetitive nonindividualized routine presentation of fundamentals, they can more efficiently use their clinical judgment as a learning tool.

Programming, or the use of audiovisual aids, is not a panacea for unsatisfactory student:faculty ratios. The nursing student who is motivated to obtain her professional skills will learn from any teaching method. This new orientation provides a base of information on which both student and teacher can build, thereby allowing the student to give more effective nursing care earlier than in the more traditional approach. It is this factor, along with the conservation of faculty time and the more effective and economical use of student-teacher contact time that are the most beneficial aspects of this approach. 


\section{References}

1. Gold, M.: Management Development Seminar. Magee-Womens Hospital, March 26, 1969 (unpublished lecture)
2. Simonds, A.: "Two Methods of Teaching in the O.R." Nurs Outlook 18:29-31, 1970

3. Sullivan, J. A., and M. H. Weber: "Nursing Bag Technique-Self Taught." Nurs Outlook $18: 59,1970$

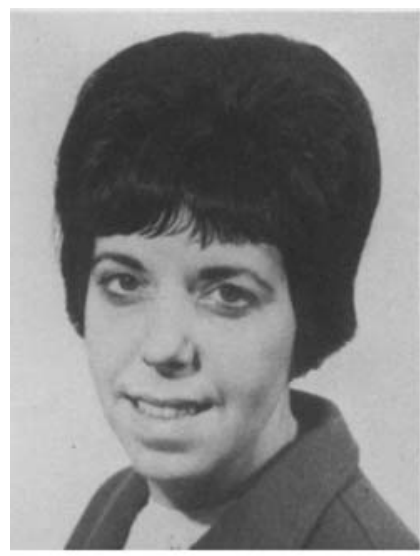

Margaret Brackin (BSN, University of Pittsburgh School of Nursing; MPH, University of Michigan, Ann Arbor) is currently Obstetric-Gynecology Nurse Practitioner at McKeesport Hospital, McKeesport, Pennsylvania. At the time of this project she was Assistant Professor in Obstetric Nursing, University of Pittsburgh School of Nursing.

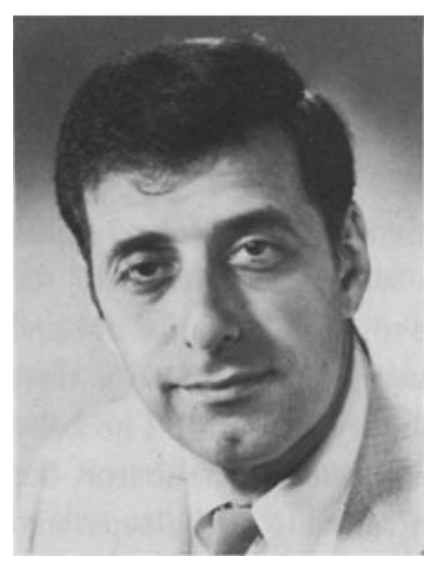

Ronald Chez (BA, Johns Hopkins University; $M D$, Cornell University School of Medicine) is Chief of Pregnancy Research Branch, National Institutes of Child Health and Human Development, Bethesda, Maryland. Previously, be was Professor of Obstetrics and Gynecology and Associate Dean of Academic Affairs at the University of Pittsburgh application of audiovisual techniques to a core School of Medicine. His interests include the clinical clerkship in medical school. 